\title{
Detection of Human Herpesvirus 6 in Cerebrospinal Fluid of Children With Possible Encephalitis
}

\author{
Jila Yavarian ${ }^{1}$; Nastaran Gavvami ${ }^{1}$; Setareh Mamishi ${ }^{2, *}$ \\ ${ }_{1}$ Virology Department, School of Public Health, Tehran University of Medical Sciences, Tehran, IR Iran \\ ${ }_{2}^{2}$ Pediatrics Medical Center, Tehran University of Medical Sciences, Tehran, IR Iran \\ ${ }^{*}$ Corresponding author: Setareh Mamishi, Pediatrics Medical Center, Tehran University of Medical Sciences, Tehran, IR Iran. Tel: +98-2142933103, Fax: +98-2188962343, E-mail: \\ nilj57156@yahoo.com
}

Received: April 28, 2013; Revised: June 16, 2013; Accepted: June 17, 2013

\begin{abstract}
Background: Encephalitis is swelling and inflammation of brain, usually due to viral infection. Viral encephalitis symptoms could be fever, headache, altered level of consciousness, and seizures.

Objectives: The aim of this study was detection of human herpesvirus-6 (HHV-6) DNA in cerebrospinal fluid (CSF) of patients with symptoms of possible acute encephalitis and without typical signs or symptoms of roseola infantum, using real-time polymerase chain reaction (PCR).

Patients and Methods: We studied children two years old or younger, admitted to the pediatric emergency ward with encephalitis-like symptoms. Our evaluation included detection of HHV-6 in CSF of these patients. After DNA extraction, real-time PCR was performed with primers and a probe specific for the U22 open reading frame of both HHV-6A and B.

Results: From a total of 114 patients, HHV- 6 was detected in 10 (8.8\%), 90\% of which were boys with mean age 7.7 months and median of 7.5 months. No significant differences were found in clinical presentations and laboratory findings between the patients positive and negative for HHV-6. All the children had complete recovery without neurological deficit or death.

Conclusions: According to this research and prevalence of HHV-6 in children, evaluation of CSF (detecting the HHV-6 DNA by PCR) is recommended in patients younger than 13 months with possible encephalitis.
\end{abstract}

Keywords:Real-Time Polymerase Chain Reaction; Human Herpesvirus6; Cerebrospinal Fluid; Encephalitis

\section{Background}

Encephalitis is the acute inflammation of brain. This disease may lead to recovery, permanent sequela, or death. Encephalitis is one cause of epilepsy in the United States, as the central nervous system (CNS) trauma; however, there are 1.4 million cases of head injury in comparison with less than 50000 cases of CNS infection per year. The exact etiology of this disease is unknown and might be due to infective or noninfective causes, but viruses have been mostly implicated. The most common viruses involved are human herpesviruses, flaviviruses, enteroviruses, and alphaviruses. Less common viral agents include influenza viruses, adenoviruses, rabies virus, lymphocytic choriomeningitis virus, measles, rubella and mumps.

Vaccinations have dramatically decreased encephalitis because of childhood diseases such as mumps, measles and rubella. Between herpesviruses, human herpesvirus-6 (HHV-6) is found in cerebrospinal fluid (CSF) of $10 \%$ of patients with suspected viral CNS diseases. Ishiguro et al. (1) reported the first case of encephalitis with HHV-6 infection in 1990. Viral encephalitis symptoms could be fever, headache, altered level of consciousness, and seizures (2). Antiviral treatment for herpes encephalitis is ganciclovir, acyclovir and foscarnet. With production of new antiviral drugs, correct and timely diagnosis of the disease would be important for patients' management (2).

HHV-6 is classified in the roseolovirus genus of the betaherpesvirus subfamily. It has been linked to different CNS diseases such as meningitis, encephalitis, and multiple sclerosis, as well as psychological disorders. HHV-6 primary infection manifests itself as roseola infantum with common symptoms of fever and rash in children between six months and two years old. This disease itself is usually benign, but some major complications such as seizures, bulging of the anterior fontanel, and encephalitis have been reported after this disease (3). The question is that whether HHV-6 could cause encephalitis in the absence of roseola infantum.

The diagnosis could be obtained by detection of viral nucleic acid as well as antibody or virus isolation from CSF or brain tissue. Because of limitations in virus isolation and serological tests, polymerase chain reaction (PCR) has been widely used in clinical diagnosis of viruses. Even with this sensitive and specific technique, 30-60\% of patients with encephalitis remain undiagnosed (4).

\section{Objectives}

The aim of this study was detection of HHV-6 DNA in CSF

Copyright (C) 2014, Ahvaz Jundishapur University of Medical Sciences; Published by Kowsar Corp. This is an open-access article distributed under the terms of the Creative Commons Attribution License, which permits unrestricted use, distribution, and reproduction in any medium, provided the original work is properly cited. 
of patients with symptoms of possible acute encephalitis, using real-time PCR.

\section{Patients and Methods}

\subsection{Patients and Samples}

In this cross-sectional study, all children aged $\leq 2$ years with encephalitis-like symptoms (temperature $>38^{\circ} \mathrm{C}$, convulsion, and some with altered levels of consciousness), admitted to the emergency ward of Children Medical Center of Tehran University of Medical Sciences between March 2010 and March 2011 were enrolled. All the patients were hospitalized. During hospitalization, special forms were filled to record the history and demographic information (age and sex) as well as clinical and laboratory findings (symptoms, CSF cell counts, and glucose and protein levels). The final diagnosis was made by the pediatrician. Lumbar puncture was performed on the first day of admission and CSF specimens were collected from all patients; then, they were sent to the Virology Department, School of Public Health, Tehran University of Medical Sciences, and stored at $-70^{\circ} \mathrm{C}$. All the parents signed the informed consents.

\subsection{Nucleic Acid Extraction}

DNA was extracted from $140 \mu \mathrm{L}$ of each sample with high pure viral nucleic acid kit containing proteinase $\mathrm{K}$ (Roche, Germany), according to the manufacturer's instruction. When extracting the viral DNA, proteinase $\mathrm{K}$ was added to the sample before adding to the column.

\subsection{Real-Time Polymerase Chain Reaction}

The CSF specimens were tested for HHV-6 DNA, using Taq Man real-time PCR. The primers and the probe were directed against the U22 open reading frame of both HHV-6A and B; forward primer: $5^{\circ}$ - TCG AAA TAA GCA TTA ATA GGC ACA CT-3`' reverse primer: $5^{\prime}-\mathrm{CGG}$ AGT TAA GGC ATT GGT TGA $-3^{-}$, and Taq Man probe: FAM-CCA AGC AGT TCC GTT TCT CTG AGC CA-TAMRA, which amplified a 99bp fragment. The probe was labeled at the 5 ' end with 6-carboxyfluorescein as the reporter dye and at the 3' end with 6-carboxytetramethylrhodamine as the quencher. An adenine-to-guanine substitution at position 11 of the HHV6B sequence in the reverse primer and in the probe, as well as an AC-to-GT substitution at positions 13 and 14, were accepted for designing the primer-probe (5).

The DNA extract $(7 \mu \mathrm{L})$ was amplified by real-time PCR in a $25-\mu \mathrm{L}$ reaction mixture, containing $12.5 \mu \mathrm{L}$ of Quanti fast probe PCR master mix (QIAGEN, Germany), $4 \mu \mathrm{L}$ of forward and reverse primers (10 pmol), $1 \mu \mathrm{L}$ of probe (10 pmol), and $0.5 \mu \mathrm{L} d \mathrm{ddH}_{2} \mathrm{O}$ in ABI Step One Plus ${ }^{\mathrm{TM}}$ (Applied Biosystems, U.S.A) machine. The thermocycling process consisted of PCR initial heat activation for three minutes at $95^{\circ} \mathrm{C}$, followed by 40 cycles of denaturation at $95^{\circ} \mathrm{C}$ for 15 seconds, annealing at $56^{\circ} \mathrm{C}$ for 30 seconds, and exten- sion at $60^{\circ} \mathrm{C}$ for 30 seconds. The HHV- 6 positive control was purchased from Vircell Microbiology Company. The concentration of HHV-6 control DNA was 104 copies/ $/ \mathrm{L}$; after dilution, we had 10 copies/ $\mu \mathrm{L}$, which was positive in cycle threshold (CT): 20.

\section{Results}

One hundred and fourteen children, two years old or younger, with symptoms of possible encephalitis, were enrolled in this study. All the patients underwent lumbar puncture for ruling out the encephalitis. Of the total patients, 68 were male and 46 were female, of which, 39 were older and 75 younger than 12 months old. The mean age was 10.9 and the median of age was 11 months old. Eleven patients had history of vaccination in the past two days, six of which were MMR, four were DPT, and one was Influenza vaccine. The disease incidence was $42.1 \%$ in autumn, $35.08 \%$ in winter, $17.54 \%$ in spring, and $5.26 \%$ in summer.

In three of the children rash was identified, which was not specific for roseola infantum. In 10 (8.8\%) children HHV-6 was detected from CSF. These children were younger than 13 months old (the youngest one was two and the oldest 13 months old) and 90\% of them were boys. The mean age was 7.7 and median was 7.5 months old. Their average temperature $\left(38.9^{\circ} \mathrm{C}\right)$ at the time of admission was not significantly different from the temperature in the children with negative HHV-6. In HHV-6-positive patients, the incidence was $70 \%$ in winter, $20 \%$ in autumn, and $10 \%$ in summer. Two patients had fever two days before the convulsion and eight had fever at the day of convulsion. Of the 114 children, febrile convulsion (FC) was the first episode in 95 (83.33\%) and the second in 19 (16.66\%). HHV-6 DNA was found in eight of 95 patients with first FC episode and two of 19 with second episode. The range of white cell count of the HHV-6-negative group was $16679 \pm 11880 \mathrm{cell} / \mathrm{mm}^{3}$ and for the HHV-6-positive children it was $11986 \pm 8842 \mathrm{cell} / \mathrm{mm}^{3}$. All the 114 patients had FC, 10 had loss of consciousness, 16 coryza, 20 cough, 15 diarrhea, and eight vomiting. Among HHV-6-positive patients, one had loss of consciousness, two coryza, two cough, and one diarrhea. Table 1 shows the demographic and clinical parameters of the patients.

\section{Discussion}

Encephalitis is an acute inflammation of brain; it is a crucial cause of acute symptomatic seizures and the subsequent epilepsy. Annually, 7.3 per 100000 people are hospitalized in the United States because of encephalitis (2). Clinical syndromes of acute childhood encephalitis may range from mild illness including fever, convulsion and varying degree of consciousness, to a devastating disease resulting in death (4). These symptoms might be due to a variety of noninfective and infective causes. Having information about the disease etiology may be helpful in determining the therapeutic regimens as well as preventive advises. Certain virus families, especially herpes viruses 
Yavarian J et al.

\begin{tabular}{|c|c|c|}
\hline Variables & All the Patients $(n=114)$ & HHV-6-Positive Patients $(n=10)$ \\
\hline \multicolumn{3}{|l|}{ Gender } \\
\hline Male & $68(59.64)$ & $9(90)$ \\
\hline Female & $46(40.36)$ & $1(10)$ \\
\hline Mean age, $\mathrm{m}$ & 10.9 & 7.7 \\
\hline Median of age, $\mathrm{m}$ & 11 & 7.5 \\
\hline \multicolumn{3}{|l|}{ Season } \\
\hline Spring & $20(17.54)$ & $0(0)$ \\
\hline Summer & $6(5.26)$ & $1(10)$ \\
\hline Fall & $48(42.12)$ & $2(20)$ \\
\hline Winter & $40(35.08)$ & $7(70)$ \\
\hline \multicolumn{3}{|l|}{ Primary manifestations } \\
\hline Fever & $114(100)$ & $10(100)$ \\
\hline Fever and convulsion & $114(100)$ & $10(100)$ \\
\hline Loss of consciousness & $10(8.77)$ & $1(10)$ \\
\hline Fever and diarrhea & $15(13.15)$ & $1(10)$ \\
\hline Fever and vomiting & $8(7.01)$ & $0(0)$ \\
\hline Fever and cough & $20(17.54)$ & $2(20)$ \\
\hline Fever and coryza & $16(14.03)$ & $2(20)$ \\
\hline Rash & $3(2.63)$ & $0(0)$ \\
\hline \multicolumn{3}{|l|}{ Episode of seizure } \\
\hline One episode & $95(83.33)$ & $8(80)$ \\
\hline More than one episode & $19(16.66)$ & $2(20)$ \\
\hline \multicolumn{3}{|c|}{$\begin{array}{l}\text { The interval between fever and con- } \\
\text { vulsion }\end{array}$} \\
\hline Less than $24 \mathrm{~h}$ & $100(87.71)$ & $8(80)$ \\
\hline More than $24 \mathrm{~h}$ & $14(12.28)$ & $2(20)$ \\
\hline Laboratory findings & Mean \pm SD & Mean \pm SD \\
\hline $\mathrm{WBC}$, cell $/ \mathrm{mm}^{3}$ & $16679 \pm 11880$ & $11986 \pm 8842$ \\
\hline PMN, \% & $52.1 \pm 19.3$ & $45 \pm 7$ \\
\hline Lymphocyte,\% & $41.1 \pm 26.7$ & $47 \pm 7$ \\
\hline $\mathrm{ESR}, \mathrm{mm} / \mathrm{h}$ & $77 \pm 16$ & $16 \pm 6$ \\
\hline \multicolumn{3}{|l|}{ CSF analysis } \\
\hline $\mathrm{WBC}$, cell $/ \mathrm{mm}^{3}$ & $130 \pm 27$ & $100 \pm 25$ \\
\hline $\mathrm{RBC}$, cell $/ \mathrm{mm}^{3}$ & $345 \pm 61$ & $297 \pm 74$ \\
\hline Sugar, mg/dL & $62 \pm 17$ & $57 \pm 7$ \\
\hline Protein, $\mathrm{mg} / \mathrm{dL}$ & $22 \pm 30$ & $22 \pm 14$ \\
\hline History of vaccination & $11(9.64)$ & $0(0)$ \\
\hline Encephalitis & $0(0)$ & $0(0)$ \\
\hline Complete recovery & $114(100)$ & $10(100)$ \\
\hline
\end{tabular}

\footnotetext{
a Abbreviations: CSF: cerebrospinal fluid; ESR: erythrocyte sedimentation rate; HHV-6: human herpesvirus 6; PMN: polymorphonuclear leukocytes; RBC: Red blood cell; WBC: white blood cell.

$\mathrm{b}$ Data are presented as Mean \pm SD or No. (\%).
} 
such as HHV-6, can cause encephalitis (5). After exclusion of noninfectious, bacterial, and fungal causes of encephalitis, viral diagnosis could be commonly achieved by PCR of CSF samples.

Seroepidemiological surveys have shown that HHV-6 can infect almost all children up to two years of age. This virus causes roseola infantum as the primary infection, but it can cause some neurological disorders too (6). Seizures, meningoencephalitis, bulging of the anterior fontanel, and encephalopathy are the most common manifestations. In one third of children younger than two years old with FCs, HHV-6 was detected. The mechanism through which this virus causes CNS complications is unclear, but it seems to be the result of direct invasion of CNS. Its multiple manifestations as well as lack of routine diagnostic tests resulted in costly and lengthy evaluations and hospitalizations; thus, understanding of the frequency and consequences of HHV-6 infection could be helpful in diagnosis and management of patients (7).

Molecular methods of detection, especially PCR, have been established for diagnosis of CNS infections. Even with the best and most specific methods, 30-60\% of patients with suspected viral encephalitis will be undiagnosed (4). In this research, HHV-6 was identified by realtime PCR in 10 of 114 CSF specimens from children who showed symptoms of possible encephalitis (incidence: 8.8\%).Encephalitis due to HHV-6 infection has been reported by several studies. In some of them, patients completely recovered, and in some others, neurologic sequela and death were reported. The HHV-6 DNA was identified in CSF of several patients with PCR, revealing the direct viral invasion to CNS $(8,9)$.

In a study by Yoshikawa et al. in 2009 (10), 86 cases of exanthema subitum with encephalopathy were evaluated, among which, the HHV-6 DNA was detected in 21 patients with two deaths. In our research, all the patients survived and there was no confirmed encephalitis and death. In another study by Suga et al. (11) on 21 patients with exanthema subitum and CNS complications, nine cases were HHV-6-positive for CSF test, four had encephalitis, 17 had complete recovery, one case with encephalitis developed epilepsy, and one case died. A study by Noorbakhsh et al. (12) on CSF samples of 150 children with meningoencephalitis in Tehran showed that 9 (6\%) patients were positive for the HHV-6 DNA. Encephalitis is important, both in the acute phase and the long term neurologic sequels.

This is obviously an area of high clinical importance, requiring further investigations for diagnosis and treatment.HHV-6 is sensitive to ganciclovir and foscarnet and insensitive to acyclovir, same as cytomegalovirus (13). Yoshida et al. (14) showed that HHV-6 was highly sensitive to cidofovir. There are not enough reports about the outcome of HHV-6 treatment with antivirals. This lack of information might be due to the fact that studies on HHV-6 have been retrospective and there is not a routine laboratory test for identifying the virus in suspected patients. This was a cross-sectional descriptive study on im- munocompetent children, revealing the prevalence of HHV-6 in children less than two years old with possible encephalitis. No significant differences could be found in clinical presentations and laboratory findings between the ten patients with and the 104 patients without HHV- 6 infection. All the patients had complete recovery without neurological deficit or death; thus, we can conclude that all the patients were FC cases, some of which had postictal drowsiness.

The small sample size was one of the limitations of this study. Further prospective studies on immunocompromised children are recommended for comparing the results between immunocompetent and immunocompromised children. Another issue is recognizing the common viruses such as herpes simplex virus, enteroviruses, etc. in follow up studies, to find the coinfection and other possible factors involved in this disease. According to this study, evaluation of CSF (detecting the HHV-6 DNA by PCR) is recommended in children younger than 13 months old with possible encephalitis, for initiating the antiviral treatment. We should follow up for identifying the type of viruses (HHV-6 A or B) as well as the prevalence of HHV-6 DNA integration into the germline, which can permanently turn the individual into HHV-6-positive.

\section{Acknowledgements}

The authors thank all the staff of the National Influenza Center, School of Public Health, Tehran University of Medical Sciences for their helps.

\section{Author's Contributions}

Jila Yavarian: study design, experiments performances, writing the manuscript; Nastaran Gavvami: DNA extraction; Setareh Mamishi: patients' diagnoses and sampling.

\section{Funding/Support}

All phases of this study were supported by Tehran University of Medical Sciences, Grant No. 89-03-27-11092.

\section{References}

1. Ishiguro N, Yamada S, Takahashi T, Takahashi Y, Togashi T, Okuno T, et al. Meningo-encephalitis associated with HHV-6 related exanthem subitum. Acta Paediatr Scand. 1990;79(10):987-9.

2. Dupuis M, Hull R, Wang H, Nattanmai S, Glasheen B, Fusco H, et al. Molecular detection of viral causes of encephalitis and meningitis in New York State. J Med Virol. 2011;83(12):2172-81.

3. Hall CB, Caserta MT. Exanthema subitum (roseola infantum). Am J Dis Child. 1939;58(5):983-93.

4. Misra UK, Tan CT, Kalita J. Viral encephalitis and epilepsy. Epilepsia. 2008;49 Suppl 6:13-8.

5. Studahl M, Hagberg L, Rekabdar E, Bergstrom T. Herpesvirus DNA detection in cerebral spinal fluid: differences in clinical presentation between alpha-, beta-, and gamma-herpesviruses. Scand J Infect Dis. 2000;32(3):237-48.

6. Yamanishi K. Pathogenesis of human herpesvirus 6 (HHV-6). Infect Agents Dis. 1992;1(3):149-55.

7. Hall CB, Long CE, Schnabel KC, Caserta MT, McIntyre KM, Costanzo MA, et al. Human herpesvirus- 6 infection in children. A pro- 
spective study of complications and reactivation. $N$ Engl J Med. 1994;331(7):432-8.

8. Asano Y, Yoshikawa T, Kajita Y, Ogura R, Suga S, Yazaki T, et al. Fatal encephalitis/encephalopathy in primary human herpesvirus-6 infection. Arch Dis Child. 1992;67(12):1484-5.

9. Yoshikawa T, Nakashima T, Suga S, Asano Y, Yazaki T, Kimura H, et al. Human herpesvirus-6 DNA in cerebrospinal fluid of a child with exanthem subitum and meningoencephalitis. Pediatrics. 1992;89(5 Pt 1):888-90.

10. Yoshikawa T, Ohashi M, Miyake F, Fujita A, Usui C, Sugata K, et al. Exanthem subitum-associated encephalitis: nationwide survey in Japan. Pediatr Neurol. 2009;41(5):353-8.
11. Suga S, Yoshikawa T, Asano Y, Kozawa T, Nakashima T, Kobayashi I, et al. Clinical and virological analyses of 21 infants with exanthem subitum (roseola infantum) and central nervous system complications. Ann Neurol. 1993;33(6):597-603.

12. Noorbakhsh S, Ebrahimi Taj F, Monavari HR, Tabatabaei A. . HHV 6 and HHV-7 PCR in CSF of children. Tehran Iran: 2013..

13. Osman H. Human Herpesvirus 6 and Febrile Convulsions. Herpes. 2000;7(2):33-7.

14. Yoshida M, Yamada M, Tsukazaki T, Chatterjee S, Lakeman FD, Nii $S$, et al. Comparison of antiviral compounds against human herpesvirus 6 and 7. Antiviral Res. 1998;40(1-2):73-84. 